\title{
A Multi-Technique Bibliometric Analysis of The Field of Distributed Work: Where it All Began, Where is it Now and Where is it Going
}

\author{
Lamovšek Amadeja \\ School of Economics and Business, University of Ljubljana \\ Kardeljeva ploščad 17, 1000 Ljubljana, Slovenia \\ amadeja.lamovsek@ef.uni-lj.si
}

\begin{abstract}
This review focuses on the growing field of distrubuted work, made even more relevant in light of the current pandemic. Many different definitions, labels, and conceptualizations of distributed work exist, resulting in a fragmented field, threatened by a proliferation of concepts. Prior reviews either tackle a limited scope of phenomena or review approaches, are narrative/subjective/not systematic, lacking objectivity, comprehensiveness and reproducibility, or recency. Our study attempts to advance the current overview of the field by providing a comprehensive review of the development and current state of the field. We do so by applying a combination of three bibliometric techniques-co-citation analysis, co-word analysis, and bibliographic coupling-applied against the backdrop of the invisible colleges framework. This produces an integrative and holistic framework of the field of distributed work, portraying its historic development and theoretical background, conceptual space and nomological net, guiding future research on this and connected topics.
\end{abstract}

\section{Introduction}

Information and Communications Technology (ICT) has become a key component of modern businesses. It is changing the global flow of information, trade, investment, and ways to obtain firms' competitive advantage [1], [2]. It has also changed the nature of work and, along with new organizational approaches, challenged traditional thinking of managers [3], [4]. By using modern technologies (user friendly computers, virtual private connections, digital telephone systems, electronic collaboration systems, etc.) employees can communicate and cooperate with their co-workers and managers continuously and constantly [5]. This resulted in the establishment of distributed work, defined as an arrangement that allows employees and their tasks to be distributed away from the physical location of the company [6]. Many different forms, definitions and conceptions of distributed work exist in the literature and practice, e.g., remote work, telework, telecommuting, distance work, work from home, digital work, virtual work, etc. [7]-[9].

Common to these conceptualizations is the premise that individuals working together are not all colocated, and thus rely on computer-mediated communication technology for planning and coordinating with team members, as well as for informal and social interactions [10]. Thus, adapting jobs for telework is necessary for organizations that want to take advantage of new opportunities, increase their business sustainability and keep ahead of the curve [11]. The first case of teleworking was recorded in 1877, when the president of the bank in Boston had his business telephone installed at home, and has increased considerably over the last decade [12].

Distributed work has positive (e.g., less stress, lower costs of transportation, lower costs of clothes, more flexibility, higher work satisfaction) and negative consequences (e.g., social isolation, costs of technology, challenges with ergonomics) for employees [13]-[16]. While remote working is considered to be more adaptable, enables independence and self-organization of employees, and in certain cases, greater efficiency, these benefits came at the cost of work intensification and an increased inability to remove oneself from work [17].

\subsection{Existing reviews on distributed work and related terms}

What we currently know about the research area of distributed work is that it is a rapidly growing field of academic endeavor and practice, made even more relevant by recent changes in today's work environment and workplaces. At the same time, many different definitions, labels, and conceptualizations of distributed work exist, resulting in a fragmented field that is threatened by a proliferation of concepts. With such proliferation looming, and reviews being specifically focused only on specific subdomains, researchers are unlikely to see the entire conceptual landscape and fully 
understand the interconnections among different concepts describing remote work, their background and conceptual space. There are already several reviews addressing some of these concepts [6], [18]-[24]. However, they either tackle a limited scope of distributed work phenomena, are narrative/subjective/not systematic, thus lack objectivity, comprehensiveness and reproducibility, or are not very recent.

A review by Shin, El Shawy, Liu Sheng and Higa (2000) is rather outdated and focuses only on three terms: telework, telecommuting and virtual organization. Moreover, it is narrative and qualitative. A study by Laine (2009) focuses only on the phenomenon of virtual communities and does not capture the whole picture of remote work. A study by Charalampous, Grant, Tramontano, and Michailidis (2019) systematically examines remote e-workers in the context of well-being at work, and is thus limited in scope of this specific research question. A review by Raghuram, Hill, Gibbs, and Maruping (2019) recently attempted to address some of these issues by providing a quantitative review of "virtual work" based on a single bibliometric technique of co-citation analysis. Even more recently, a study by Abarca, Palos-Sanchez and Rus-Arias (2020) looks at working in virtual teams and a study by Santana and Cobo (2020) looks at the future of work, including remote working in the analysis as one of the subsections of future of work. Both of these, albeit very recent and touching upon some of the concepts under investigation here, are clearly different in scope.

\subsection{Identified gaps}

The study of Raghuram and colleagues (2009) is the most connected to ours. It is importantly contributing to our understanding of the concept of virtual work by presenting the intellectual structure which this field is based upon, and conducts a comparative review of the identified sub-fields (Telecommuting, Computer-Mediated Communication and Virtual teams) to propose a systematic approach for bridging research across clusters of different approaches to studying virtuality. Nonetheless, many issues and gaps worth addressing remain.

First, their 'overview of the virtual work field' is based on co-citation analysis, one of the bibliometric techniques. The authors interpreted its results as 'research clusters constituting the field of virtual work'. However, co-citation analysis [25] is a bibliometric technique that looks at the theoretical foundations, intellectual roots of a certain scientific domain by identifying its core works. i.e., studies that the field cites and is built upon, not what a field actually consists of. Current state-of-the-art of the field with current trends and hot topics remains to be examined.
Secondly, their analysis is limited in keywords they focused on, which results in important conceptual deficiency in terms of representing a holistic allencompassing portrayal of the field. Specifically, their search does not include key terms that could importantly capture aspects of distributed work related to remote work or work from home; these have been made even more relevant in the light of the current pandemic. Last but not least, while the co-citation results of Raghuram, Hill, Gibbs, and Maruping (2019) provide a comprehensive (bundled) insight into the field's theoretical foundations, our understanding of how the field evolved over time - patterns of evolution of its schools of thought and sub-sections, their theoretical background, shifts over time and actual content remains limited.

\subsection{Research questions and our potential contributions}

This paper attempts to provide a comprehensive overview of the development and current state of distributed work in an attempt to advance the current overview of the field. To do so, we posit the following three research questions: (1) What is the intellectual structure of the field of distributed work, and how have its theoretical foundations developed and transformed over time? (2) What are the topics associated with a distributed work? and (3) What is the intellectual structure of recent/emerging literature on the field of distributed work? We answer them by applying a combination of three bibliometric techniquesdocument co-citation analysis, co-word analysis, and bibliographic coupling - applied against the backdrop of the invisible colleges framework [26]. This triangulation of methods allows us to address each research question with a specific technique, and overall, examine the cited authors, influential works, and the actual content of the documents to capture structural and temporal components simultaneously. This has the potential to contribute to the literature in four ways.

First, we intend to corroborate the study of Raghuram, Hill, Gibbs \& Maruping (2019) by providing an accurate and appropriate account of co-citation analysis. Second, we intend to expand their search in our analysis with other related and relevant terms, namely: work from home, home working, working remotely, and e-work. Third, we intend to further advance the exploration of the evolution of the field, mapping its trajectory and development by applying the invisible colleges framework [26]. Fourth, we add two additional techniques - co-word analysis and bibliographic coupling - that allow us to complement our investigation of the past/theoretical foundations by exploring the semantic (conceptual) space and current hot topics in the literature. 


\section{Methodology}

To address these challenges in the current overview of this important field, we conducted three bibliometric techniques, namely: co-citation, cooccurrence and bibliographic coupling. To do so we used Web of Science (database most used in biliometric studies[27]) for data search and export, and VOSviewer software [28] for analysis and visualization. VOSviewer visualizes data on the basis of influence and proximity measures to analyse a large variety of bibliometric networks, ranging from networks of citation relations between publications or journals to networks of coauthorship relations between researchers or networks of keywords co-occurrence [28]. Three analyses were performed.

Final search terms included "virtual team*" OR "virtual group*" OR "virtual work*" OR "distributed team*" OR "distributed group*" OR "distributed work*" OR "mobile work*" OR "remote work" "dispersed group*" OR "dispersed team*" OR "dispersed work*" OR "technology-mediated work*" OR "technology mediat*team*" OR "technologymediated group*” OR “computer-mediated group*” OR "computer mediat* team*" OR "computer mediat* work" OR "telework*" OR "telecommut*" OR "distance work*" OR "distance team*" OR "work* from home" OR "home working" OR "working remotely" OR "e-work" ".

First, in order to test the semantic similarity between articles and to obtain a dynamic representation of the historic perspective of remote work, we performed a co-citation analysis [25] on secondary papers (i.e., those that the field cites). Using the network analysis (a graph-theoretic approach for portraying most important units of analysis and their interrelationships; [29], we (1) delineate the subfields that constitute the intellectual structure of distributed work research and identify its most important knowledge domains, (2) determine the relationships between the subfields, (3) identify papers (and authors) who play a pivotal role in bridging two or more conceptual domains of research, and (4) graphically map the conceptual foundations in order to visualize relations between intellectual domains (clusters of conceptual bases).

To get better insights at the development of distributed work, we divided the search into three temporal parts. First one included articles up until 1995, the second one from 1996 to 2010 and the third one from 2011 to 2020 . These time periods were selected in a way to produce relatively comparable time frames, with 1995 being a turning point with influential articles of Handy (1995) and Mayer, Davis and Schoorman (1995) being published, and 2010 as another one, with Barack Obama signing the Telework Enhancement Act, which transformed Federal telework to unleash its potential as a strategic intervention for supporting agency effectiveness, achieve greater flexibility in managing its workforce and helping employees enhance work-life effectiveness [30]. As expected, the first time period includes the least number of articles (592), the second one the something in between (3.649) and the last one the most (8.063). The number of articles is increasing according to the development and popularity of distributed work.

We followed the following steps: 1) create a map based on bibliographic data, 2) read data from bibliographic database files, 3) type of analysis: cocitation, unit of analysis: cited references, counting method: full counting. The 4) step was different for each time period. Time period from 1900 to 1995 had a minimum number of citations of a cited reference set on 4, time period from 1996 to 2010 had a minimum number of citations of a cited reference set on 28 , and a time period from 2011 to 2020 had a minimum number of citations of a cited reference set on 54 .

Next, in order to understand the conceptual structure of the topic of the remote work, we performed the co-occurrence of the keywords (co-word analysis) of primary documents (those that constitute the field) [31].

For that we followed next steps: 1) create a map based on bibliographic data, 2) read data from bibliographic database files, 3) type of analysis: cooccurrence, unit of analysis: author keywords, counting method: full counting, and 4) a minimum number of occurrences of a keyword set on 16.

Finally, in order to get a temporally unbiased idea of interrelationships among the articles, currently most impactful topics and ongoing trends in the field, we performed bibliographic coupling [32] which couples primary documents on the basis of overlap of their bibliographies. This enables us to offer insights into relationships among currently hot contributions as well as to identify boundary spanners within each domain and bridges between them. In this way, we detect and show the most relevant protagonists of the subfields and the pervasiveness of their influence, graphically represent relationships among the domains, as well as identify potential ways of integrating the field and bridge some currently disconnected, but conceptually related subdomains.

For that we followed next steps: 1) create a map based on bibliographic data, 2) read data from bibliographic database files, 3) type of analysis: bibliographic coupling, unit of analysis: documents, counting method: full counting, and 4) a minimum number of occurrences of a keyword set on 180 . 


\section{Results}

Our initial, preliminary results can be briefly summarized as follows. Co-citation analysis results (Figure 1; Table 1) reveal that research over the period from 1900 to 1995 has merged into three distinct clusters.

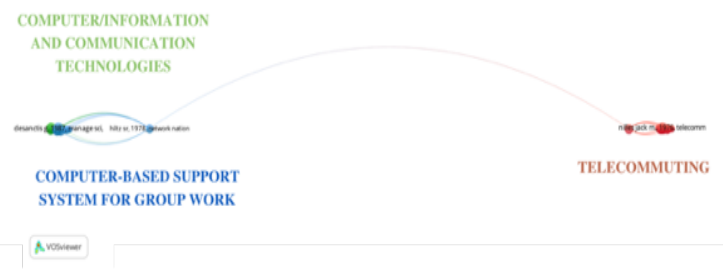

Figure 1: Co-citation map, documents between 1900 and 1995

Table 1: Results of the co-citation analysis for the distributed work field from 1900 to 1995

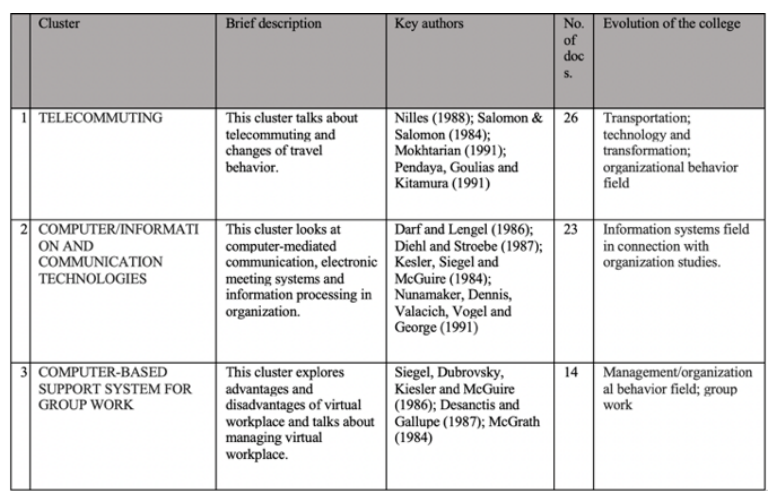

Research in the period from 1996 to 2010 (Figure 2; Table 2) was grouped into four different clusters.

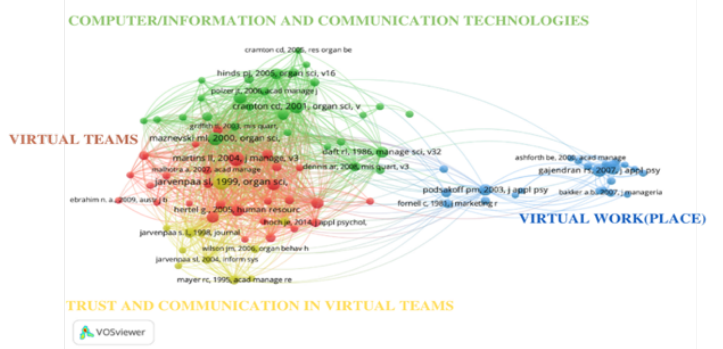

Figure 2: Co-citation map, documents between 1996 and 2010
Table 2: Results of the co-citation analysis for the distributed work field from 1996 to 2010

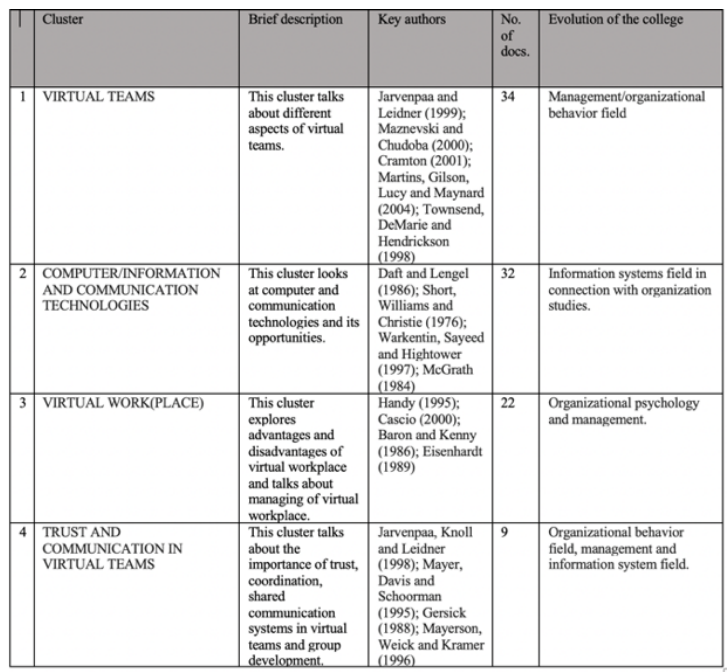

Research over the period from 2011 to 2020 (Figure 3; Table 3) can also be grouped into four different clusters.

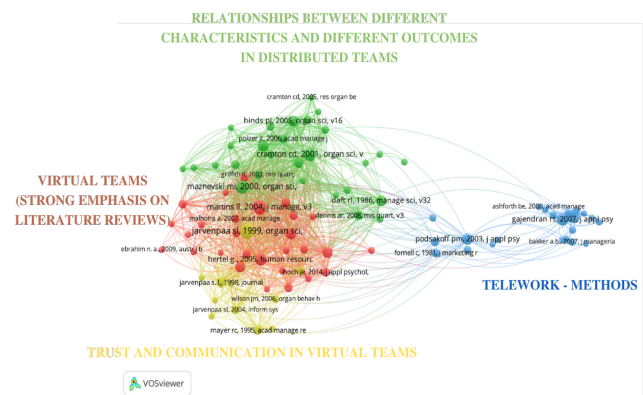

Figure 3: Co-citation map, documents between 2011 and 2020

Table 3: Results of the co-citation analysis for the distributed work field from 2011 to 2020

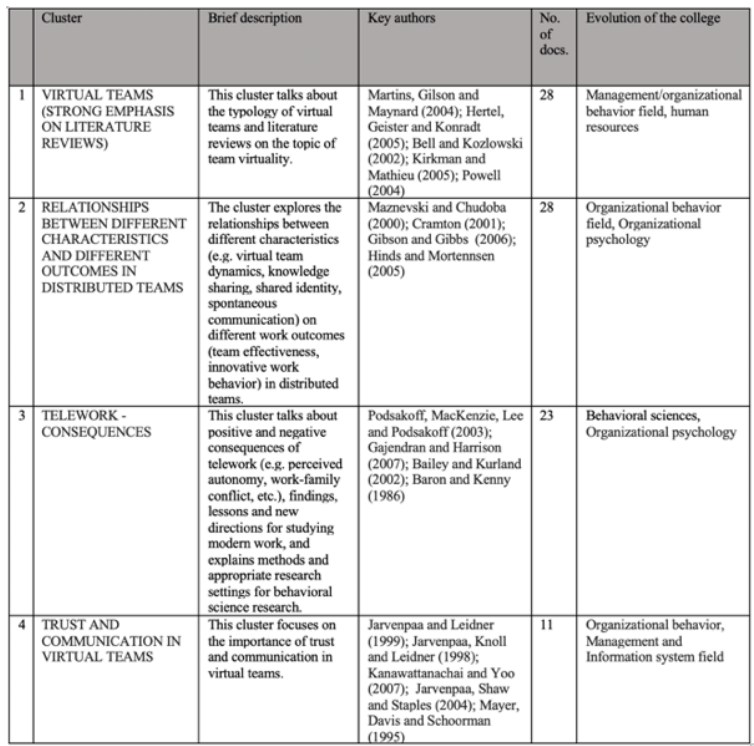


We interpret these changes over time by building on the conceptual framework of "invisible colleges" [26], [33] which can be used to explore scientific communication between scholars to elucidate the dynamic change across the three time periods of the evolution of the field. Vogel (2012) proposed seven patterns by which invisible colleges can evolve: college appearance, transformation, drift, differentiation, fusion, implosion, and revival. Preliminary analysis reveals (Figure 4) that the research of distributed work initially began in three invisible collages of telecommuting, computer/information and communication technologies, and computer-based support systems for group work, mostly from the transportation field, the information systems field, and the organizational behavior field. Each of these collages later differentiated into four somewhat narrower colleges, with the field beginning to incorporate influxes from organizational psychology and management. In the last studied decade, research on distributed work has increased significantly. Two of the collages have transformed, while two of them drifted.

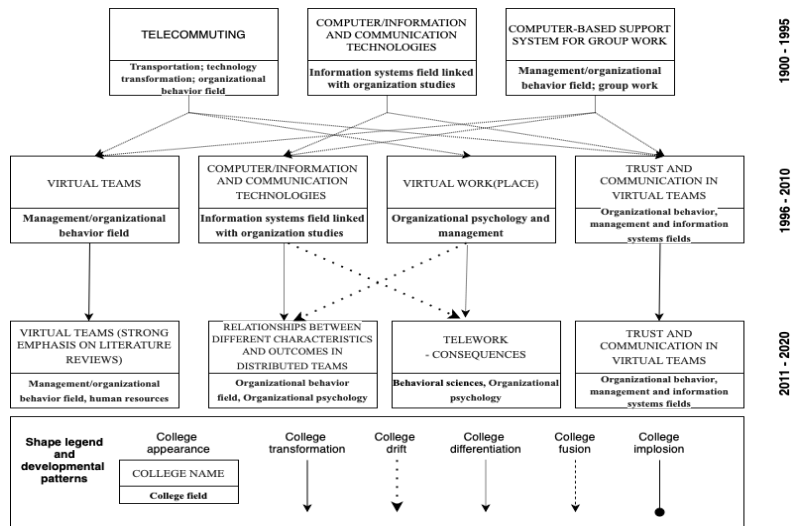

Figure 4: Development patterns of distributed work research interpreted through the invisible colleges framework

In the co-occurrence (co-word) analysis, 12.304 primary articles were analyzed. This resulted in 206 articles that formed 6 clusters. Next we eliminated keywords related to mechanical, engineering and mathematical fields, because as said before, they do not have any thematic relationship with our observed phenomena. After this exclusion, we got 194 items forming 10 clusters (Figure 5). Particularly interesting is already a large cluster related to distributed work during the pandemic, indicating that the field responded very quickly with research targeting these important topics. While most of the mainstream documents in main clusters are based upon similar theoretical backgrounds as those identified by the co-citation analysis, this thematic analysis revealed interesting additions related to currently popular trends in the field, specifically those related to safety and diversity, cognitive processing and innovation, and health/medicine.

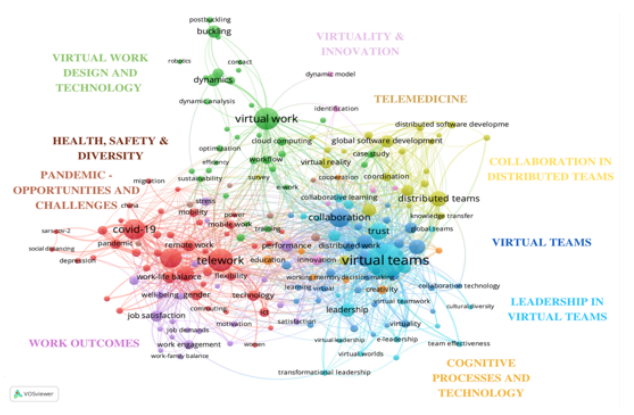

Figure 5: Co-occurrence (co-word) map

The same primary articles served as a basis for bibliographic coupling analysis, which revealed 7 clusters (Figure 6, Table 4). Similar to the co-word analysis results, cognitive processing and diversity popped up as current hot trends, while also identifying some bridging documents and authors that span across different subfields, but also revealed specific opportunities to further connect topics that are conceptually related, yet remain rather disconnected, in distinct clusters.

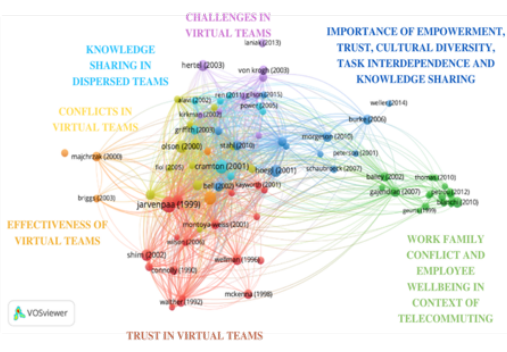

Figure 6: Bibliographic coupling map

Table 4: Results of the bibliographic coupling analysis for the distributed work field

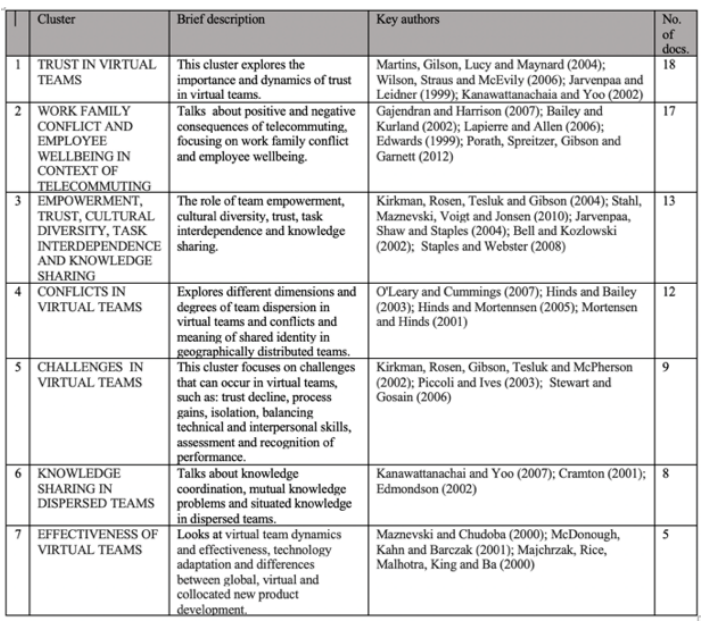




\section{Discussion}

\subsection{Intellectual structure and development of the field of distributed work over time}

We first performed co-citation analysis, for each time stamp separately. The analysis thus showed that the field of the distributed work started with research in information systems, transportation, and organizational behavior, which clearly show the importance of the first computer/information and communication technologies and the first known benefits of distributed work (e.g., less transportation). Later research was also conducted in the field of organizational psychology and management. During this time, technology became more advanced and more people were able to benefit from it, so virtual teams became more common. Managers noticed the importance of training employees to use new computer/information and communication technologies and the importance of communication and trust between team members. In the last studied decade, distributed work has become even more prevalent and most of the research is in the areas of organizational behavior, human resources, organizational psychology, and information systems. New research topics have emerged that address the work characteristics, outcomes, and consequences of new forms of work, while trust and communication remain an important point of discussion. The findings also show that there is an increasing number of literature reviews on this topic, demonstrating its importance.

To compare these findings with the study by Raghuram et al. (2019), they provide an overview of the theoretical underpinnings, but in a more summary view, indicating that the schools of thought might have remain similar over the years, which - as evidenced by our description of the field development, is not a valid assumption. Overall, this overview provides a more detailed historic portrayal and provides evidence of theoretical foundations of the field of distributed work lying in information systems, with later influxes from organizational psychology and management and information technology, finally resulting in more applied areas of organizational behavior and human resource management.

Turning our attention to the labels the field predominantly applied to denote distributed work and related concepts, research in the period from 1900 to 1995 [34]-[36] already discussed three different types of remote work options, namely work at home, satellite work centres and neighborhood work centres, but most research at that time included the term telecommuting. Researchers distinguished between two types of telecommuting, namely home-based telecommuting, where individuals work from home rather than in a traditional office, and regional center-based telecommuting, where telecommuting was classified as satellite centers, local centers, and neighborhood centers.

In the research period from 1996 to 2010 , most terms were connected to virtual wokplace, virtual teams, global virtual teams and geographically dispersed teams. In the last observed research period, from 2011 to 2020 , the term distributed work began to be used more frequtently, mostly in the context of virtual teams and telecommunications.

\subsection{Topics associated with distributed work: nomological net, connected constructs and proliferation of concepts}

The literature on distributed work spans several disciplines and has used different terminologies and conceptualizations over time, which has led to a high degree of inconsistency and arbitrariness in the use of the terms telework and telecommuting in academic studies, as some authors have already pointed out in the previous research [24], [37]-[41]. The following are just a few examples of equating terms that were not originally defined as equal, but whose actual meaning has been lost in the course of research. »Telework is sometimes reffered to as telecommuting and we will be using both terms interchangeably.« ([42], page: 77). »The most wellknown form of distributed work, telecommuting, which is also known as telework or remote work, has become a widespread practice.« ([6], page: 1524). »Flexplace, also known as teleworking or telecommuting, includes working away from a traditional office or at home, as well as virtual work using information and communication technologies." ([43], page: 2). This is a non-exhastive list of examples that indicate the fact that the meaning of terms has been lost or is not precise enough and that many authors equate terms such as telework, telecommuting, distributed work, and remote work, even though the literature is clear on the matter that these terms are related, but are not synonymous - they do not mean the exact same thing or describe the same exact phenomenon based on several key characteristics or variables denoting their potential differences. In order to get to the bottom of the matter and clarify the meaning, collected original definitions of terms, studied their content, similarities and differences, and arranged them in a way that they are logically ordered and clearly separated. 


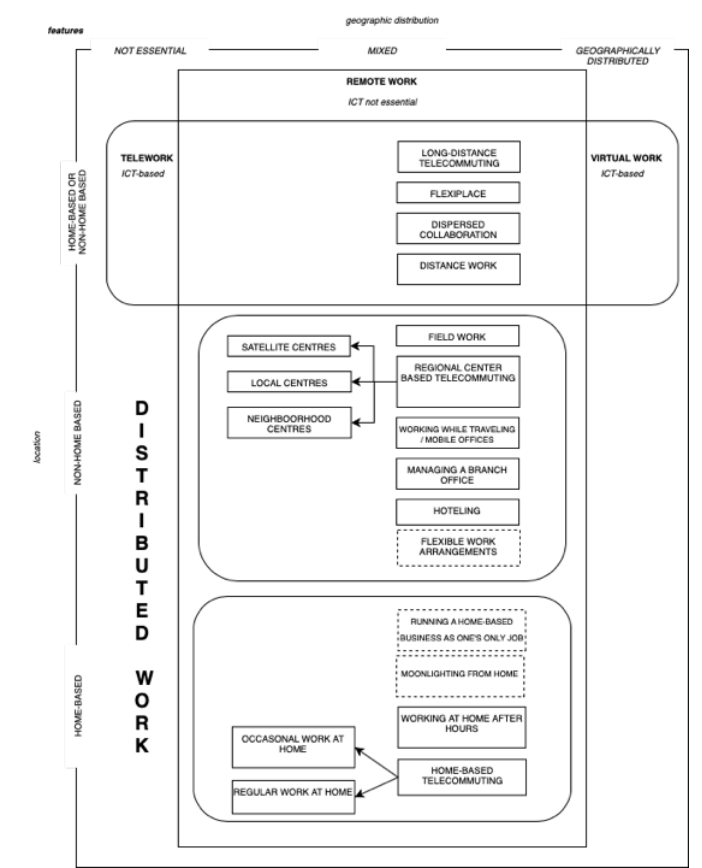

Figure 7: Distributed work concepts

We found that most concepts differ in terms of ICT use, location of work and geographical distribution, so we divided them according to these characteristics, creating the diagram (Figure 7) that reveals the main differences.

\subsection{The intellectual structure of recent/emerging literature: current trends and hot topics}

Similar to the co-word analysis results, cognitive processing and diversity popped up as current hot trends, while also identifying some bridging documents and authors that span across different subfields, but also revealed specific opportunities to further connect topics that are conceptually related, yet remain rather disconnected, in distinct clusters. We reflect on these in the future research section of our paper.

\subsection{Theoretical contributions}

On the basis of these analyses, our study attempted to advance the current overview of the field by providing an up-to-date, comprehensive and integrative review of the development and current state of the distributed work field. Combining three bibliometric techniques enabled us to tackle different but complementary research questions, such as to produce past, present, and future snapshots in order to identify the most influential topics, determine the underlying structure of the field and its development, and detect emerging topics.

First, on the basis of a correct use and interpretation of the co-citation analysis, we used this technique to identify the core theories used to inform the field, and provided a basis for portraying its evolution. We have further mapped the trajectory and development of the field by applying the invisible colleges framework. Document co-citation is a dynamic measure that changes through time as older documents accumulate more citations [44]. This suggests that cocitation frequencies can shape a certain intellectual field and are helpful in detecting shifts in certain schools of thought [45].

Second, and on a related note, we advance prior reviews in our bibliometric analysis with other related and relevant terms, namely: work from home, home working, working remotely, and e-work. This is important, conceptually, as it provides a more comprehensive account of distributed work, specifically targeting remote work/working from home. In addition, it opens up a new topic of the emerging practice of the digital nomad, which is particularly important for post pandemic times and new generations. While the longterm impacts of this massive switch to remote working are yet to be known, immediate impacts on workers' stress, burnout, loneliness, and issues related to worklife balance are evident. Our research helps in providing an evidence-based, comprehensive, and objective classification of research compartmentalized into specific clusters and sub-sections, making it easy for researchers on emerging topics to know where they can derive their theoretical ideas and insights from. Researchers can interpret our classification as a guiding framework that highlighted important opportunities regarding additional theoretical and empirical clarifications of the used distributed work concepts stemming from different backgrounds. Such an approach has the potential to take the field forward from the current situation that is ripe with proliferation of concepts - as revealed and described in detail in our discussion section.

Third, we portrayed evolutionary patterns of dynamic change in the field, showing the developmental path of specific schools of thought and how they have transformed over three time periods. Indeed, corroborating and adding to prior reviews, the distributed work research area did witness quite a few transformations of predominant theoretical influxes over time. While the field's initial intellectual structure was based mostly on transportation/information systems/telecommunication backgrounds, influxes from psychology, sociology, behavioral sciences and management/human resource management are enriching it in the last decade or so. This indicates a certain level of maturity of the field, yet unfortunately - 
as in many fields that span across disciplines and research areas - also provided a basis for (mis)interpreting specific labels or construct names in a way customary with an approach or theoretical perspectives where it has originated, or where its authors emanate from.

Last but not least, we complement this investigation and existing reviews in the field by adding two additional techniques - co-word analysis and bibliographic coupling - that allowed us to complement our investigation of the past/theoretical foundations by exploring the semantic (conceptual) space and current hot topics in the literature. This enabled us to make content-based and more objective informed suggestions about possible future avenues of research, which we provide in the following section.

\subsection{Limitations}

Despite all the strengths of our study, such as the use of multiple techniques, providing an up-to-date, comprehensive, and integrative review of the development and current state of the field of distributed work, there are still some limitations that need to be addressed. In particular, this review focuses on a limited number of keywords. We could delve deeper into the field and include some other more hidden and less used related keywords (e.g., mobile work, flexible workplace). Furthermore, although bibliometric analysis is considered unbiased and objective, this is not always the case. Publication records (citations) is known to be the best measure of influence, but sometimes some authors may cite others not only to agree with them, but also to disagree or criticize them. In this case, this chosen indicator would not show us true results. Moreover, the interpretation and labeling of the clusters is still subjective and could be done in many different ways. Also, one of the limitations is that the cooccurrence analysis only considers the authors' keywords, which means that this selection is also somehow subjective, since the authors themselves identify their keywords.

\subsection{Future research directions}

On the basis of our findings and highlighted research lacunas, we suggest several areas for future research. First, we suggest that future studies focus on the hot topics identified by bibliographic coupling that have not yet been explored sufficiently, such as (cultural) diversity, work-family conflict, trust and conflict in distributed teams, or knowledge sharing and communication in virtual teams. Authors should also take a look at the documents that are labeled as 'hot' papers in field in WoS but are due to the currency not (yet) cited as much as the oldest ones and thus were not highlighted by our study as documents that would already be highly impactful. Currently, to no surprise, those include studies that relate distributed work to adapting and responding to the COVID-19 pandemic in various settings across industries and spanning across multiple levels of analysis [46]-[49].

Second, new research could focus on further exploring clusters that are conceptually similar and could be interrelated to provide a multi-disciplinary account on phenomena they examine. Specifically, new studies could explore the relationship between technology development and work design, or - related to the point above, but in a more explicit manner - even how the current pandemic has accelerated different types of distributed work, in relation to popular topics highlighted by our analysis. This has the potential to further bridge disciplines of information systems and management/organization, and contribute to providing additional influxes from other related disciplines.

Third, last but not least, as the field of distributed work is on the rise and managers are facing problems with designing new forms of work, it would also be interesting to conduct bibliometric analyses that span across different subdomains, essentially studying overlaps between them. An example of such an approach could be a bibliometric analysis on the relationship (overlap) between the field of distributed work and the field of work design, or the research area of distributed work and collaboration, leadership or management communication. Methodological opportunities are also present that could further enhance the rigor and relevance of bibliometric review studies, such as making the content/semantic analysis obtained from the co-occurrence (co-word) analysis even more detailed and informative by connecting it with topic modeling [50]-[53].

\section{Conclusion}

Taken together, our multi-technique (co-citation, coword and bibliographic coupling) review revealed the intellectual structure of the field in an objective and allinclusive manner, addressing well-documented limitations of qualitative (narrative) reviews, and current lacunas in the literature. It allowed us to examine the development of the field in-depth, identify and interpret its current state (in terms of influential work and conceptual space), and make informed prognoses about its future outlook. This has made for an integrative and holistic framework of the past, present and future of the study of distributed work, informing practitioners about its conceptual space and nomological net, but most importantly, guide future research on this and connected topics. Our study thus provides a basis for 
future research and it further behooves us to add to our understanding of this important field.

\section{References}

[1] M. Reeves and M. Deimler, "Adaptability: The New Competitive Advantage," Harvard Business Review, pp. 135-141, 2011.

[2] H. Li, Y. Wu, D. Cao, and Y. Wang,

"Organizational mindfulness towards digital transformation as a prerequisite of information processing capability to achieve market agility," $J$. Bus. Res., vol. 122, pp. 700-712, Jan. 2021, doi: 10.1016/J.JBUSRES.2019.10.036.

[3] S. R. Barley, B. A. Bechky, and F. J. Milliken, "The Changing Nature of Work: Careers, Identities, and Work Lives in the 21st Century,"

https://doi.org/10.5465/amd.2017.0034, vol. 3, no. 2, pp. 111-115, Mar. 2017, doi: 10.5465/AMD.2017.0034.

[4] D. S. Staples, J. S. Hulland, and C. A. Higgins, “A Self-Efficacy Theory Explanation for the Management of Remote Workers in Virtual Organizations," Organ. Sci., vol. 10, no. 6, pp. 758776, 1999, doi: 10.1287/orsc.10.6.758.

[5] W. Cox, "Executive Summary: Improving Quality of Life Through Telecommuting," The information technology and innovation foundation, Washington, Jan-2009.

[6] R. S. Gajendran and D. A. Harrison, "The Good, the Bad, and the Unknown About Telecommuting: Meta-Analysis of Psychological Mediators and Individual Consequences," J. Appl. Psychol., vol. 92, no. 6, pp. 1524-1541, 2007, doi: 10.1037/00219010.92.6.1524.

[7] L. Haddon and M. Brynin, "The character of telework and the characteristics of teleworkers," New Technol. Work Employ., vol. 20, no. 1, pp. 3446, 2005, doi: 10.1111/j.1468-005X.2005.00142.x.

[8] A. Martínez-Sánchez, M. Pérez-Pérez, P. de-LuisCarnicer, and M. J. Vela-Jiménez, "Telework, human resource flexibility and firm performance," New Technol. Work Employ., vol. 22, no. 3, pp. 208-223, 2007, doi: 10.1111/j.1468005X.2007.00195.x.

[9] C. Raiborn and J. B. Butler, "A new look at telecommuting and teleworking," J. Corp. Account Financ., vol. 20, no. 5, pp. 31-39, Jul. 2009, doi: 10.1002/JCAF.20511.

[10] B. L. Kirkman and J. E. Mathieu, "The dimensions and antecedents of team virtuality," J. Manage., vol. 31 , no. 5 , pp. $700-718,2005$, doi:

10.1177/0149206305279113.

[11] P. Woolliams and F. Trompenaars, "Realizing Change Through Other Ways of Working: Reconciling Competing Demands," Organ. Dev. J., vol. 31, no. 2, pp. 6-16, 2013.

[12] J. A. Greer, T. E. Buttros, and G. Schmelzie, "Using telecommuting to improve the bottom line: the benefits definitely seem to outweigh the costs. (Cash Management).," Strateg. Financ., vol. 10, no. 83, pp. 46-50, 2002.

[13] M. E. Burbach and F. C. Day, "Does Organization Sector Matter in Leading Teleworker Teams? A Comparative Case Study," Int. J. Bus. Res. Dev., vol. 3, no. 4, pp. 8-21, 2014.

[14] L. Duxbury and M. Halinski, "When more is less: An examination of the relationship between hours in telework and role overload," Work, vol. 48, no. 1, pp. 91-103, 2014, doi: 10.3233/WOR-141858.

[15] T. W. Greer and S. C. Payne, "Overcoming telework challenges: Outcomes of successful telework strategies," Psychol. J., vol. 17, no. 2, pp. 87-111, 2014, doi: 10.1037/MGR0000014.

[16] E. E. Potter, "Telecommuting: The future of work, corporate culture, and American society," J. Labor Res., vol. 24, no. 1, pp. 73-84, 2003, doi: 10.1007/S12122-003-1030-1.

[17] A. Felstead and G. Henseke, "Assessing the growth of remote working and its consequences for effort, well-being and work-life balance," New Technol. Work Employ., vol. 32, no. 3, pp. 195-212, Nov. 2017, doi: 10.1111/NTWE.12097.

[18] V. M. G. Abarca, P. R. Palos-Sanchez, and E. RusArias, "Working in Virtual Teams: A Systematic Literature Review and a Bibliometric Analysis," IEEE Access, vol. 8. pp. 168923-168940, 2020, doi: 10.1109/access.2020.3023546.

[19] M. Charalampous, C. A. Grant, C. Tramontano, and E. Michailidis, "Systematically reviewing remote eworkers' well-being at work: a multidimensional approach," Eur. J. Work Organ. Psychol., vol. 28, no. 1 , pp. 51-73, 2019, doi: 10.1080/1359432X.2018.1541886.

[20] I. D. V. Garcia Carreño, "e-Leadership: A Bibliometric Analysis," Int. J. Adv. Corp. Learn., vol. 13, no. 1, p. 19, 2020, doi: 10.3991/ijac.v13i1.12341.

[21] M. O. J. Laine, "Virtual communities: A bibliometric analysis," Proc. 42nd Annu. Hawaii Int. Conf. Syst. Sci. HICSS, pp. 1-10, 2009, doi: 10.1109/HICSS.2009.500

[22] S. Raghuram, N. S. Hill, J. L. Gibbs, and L. M. Maruping, "Virtual work: Bridging research clusters," Acad. Manag. Ann., vol. 13, no. 1, pp. 308-341, 2019, doi: 10.5465/annals.2017.0020.

[23] M. Santana and M. J. Cobo, "What is the future of work? A science mapping analysis," Eur. Manag. J., vol. 38 , no. 6 , pp. 846-862, 2020, doi: 10.1016/j.emj.2020.04.010.

[24] B. Shin, O. R. Liu Sheng, and K. Higa, "Telework: Existing research and future directions," J. Organ. Comput. Electron. Commer., vol. 10, no. 2, pp. 85101, 2000, doi: 10.1207/S15327744JOCE1002_2.

[25] H. Small, "Co-citation in the scientific literature: A new measure of the relationship between two documents," J. Am. Soc. Inf. Sci., vol. 24, no. 4, pp. 265-269, 1973, doi: 10.1002/ASI.4630240406.

[26] R. Vogel, "The Visible Colleges of Management and Organization Studies: A Bibliometric Analysis of Academic Journals," Organ. Stud., vol. 33, no. 8, pp. 1015-1043, 2012, doi: $10.1177 / 0170840612448028$. 
[27] I. Zupic and T. Čater, "Bibliometric Methods in Management and Organization," Organ. Res. Methods, vol. 18, no. 3, pp. 429-472, 2015, doi: $10.1177 / 1094428114562629$.

[28] N. J. van Eck and L. Waltman, "Software survey: VOSviewer, a computer program for bibliometric mapping," Scientometrics, vol. 84, no. 2, pp. 523538, 2010, doi: 10.1007/S11192-009-0146-3.

[29] M. S. Christian and A. P. J. Ellis, "Examining the effects of sleep deprivation on workplace deviance: A self-regulatory perspective," Acad. Manag. J., vol. 54, no. 5, pp. 913-934, 2011, doi: 10.5465/amj.2010.0179.

[30] K. Snyder, "Enhancing Telework: A Guide to Virtual Leadership," The Public Manger, vol. 41, no. 1, pp. 11-14, 2012.

[31] M. J. Cobo, A. G. López-Herrera, E. HerreraViedma, and F. Herrera, "Science mapping software tools: Review, analysis, and cooperative study among tools," J. Am. Soc. Inf. Sci. Technol., vol. 62, no. 7, pp. 1382-1402, 2011, doi:

10.1002/ASI.21525.

[32] M. M. Kessler, "Bibliographic coupling between scientific papers," Am. Doc., vol. 14, no. 1, pp. 10 25, 1963, doi: 10.1002/ASI.5090140103.

[33] D. J. de Solla Price, "Networks of Scientific Papers," Science (80-. )., vol. 149, no. 3683, pp. 510-515, 1965, doi:

10.1126/SCIENCE.149.3683.510.

[34] P. L. Mokhtarian, "Telecommuting and Travel: State of the Practice, State of the Art,"

Transportation (Amst)., vol. 18, no. 4, 1991.

[35] J. M. Nilles, "Traffic reduction by telecommuting: A status review and selected bibliography," Transp. Res. Part A Gen., vol. 22A, no. 4, pp. 301-317, 1988, doi: 10.1016/0191-2607(88)90008-8.

[36] I. Salomon and M. Salomon, "Telecommuting: The Employee's Perspective *," Technol. Forecast. Soc. Chang., vol. 25, pp. 15-28, 1984.

[37] T. D. Allen, T. D. Golden, and K. M. Shockley, "How Effective Is Telecommuting? Assessing the Status of Our Scientific Findings," Psychol. Sci. Public Interes., vol. 16, no. 2, pp. 40-68, 2015, doi: $10.1177 / 1529100615593273$.

[38] T. Bui, K. Higa, V. Sivakumar, and J. Yen, "Beyond telecommuting: Organizational suitability of different modes of telework," in Proceedings of the Annual Hawaii International Conference on System Sciences, 1996, vol. 3, pp. 344-353, doi: 10.1109/HICSS.1996.493230.

[39] M. do Rosario Alves de Almeida, "The New Process of Work," in Encyclopedia of Networked and Virtual Organizations, G. Putin and M. M. Cunha, Eds. IGI Global, 2008, pp. 1080-1084.

[40] M. B. W. Fritz, S. Narasimhan, and H. Rhee, "Adoption of remote work arrangements: An initial analysis," in Proceedings of the Annual Hawaii International Conference on System Sciences, 1996, vol. 3, pp. 118-127, doi: 10.1109/HICSS.1996.493183.

[41] C. Sullivan, "What's in a name? Definitions and conceptualisations of teleworking and homeworking," New Technol. Work Employ., vol. 18 , no. 3 , pp. $158-165$, Nov. 2003, doi: 10.1111/1468-005X.00118.

[42] A. Templer, M. Armstrong-Stassen, K. Devine, and N. Solomon, "Telework and Teleworkers," in Changing Work Relationships in Industrialized Economies, I. U. Zeytinoglu, Ed. Philedelphia: John Benjamins publishing company, 1999, pp. 77-98.

[43] S. Azar, A. Khan, and W. Van Eerde, "Modelling linkages between flexible work arrangements' use and organizational outcomes," J. Bus. Res., vol. 91, pp. 134-143, Oct. 2018, doi: 10.1016/J.JBUSRES.2018.06.004.

[44] S. Batistič, M. Černe, and B. Vogel, "Just how multi-level is leadership research? A document cocitation analysis 1980-2013 on leadership constructs and outcomes," Leadersh. Q., vol. 28, no. 1, pp. 86103, 2017, doi: 10.1016/J.LEAQUA.2016.10.007.

[45] Y. Pasadeos, J. Phelps, and B. H. Kim, "Disciplinary Impact of Advertising Scholars: Temporal Comparisons of Influential Authors, Works and Research Networks," J. Advert., vol. 27, no. 4, pp. 53-70, 1998, doi: 10.1080/00913367.1998.10673569.

[46] M. Abdel-Basset, V. Chang, and N. A. Nabeeh, "An intelligent framework using disruptive technologies for COVID-19 analysis," Technol. Forecast. Soc. Change, vol. 163, Feb. 2021, doi: 10.1016/J.TECHFORE.2020.120431.

[47] J. Amankwah-Amoah, Z. Khan, G. Wood, and G. Knight, "COVID-19 and digitalization: The great acceleration,” J. Bus. Res., vol. 136, pp. 602-611, Nov. 2021, doi: 10.1016/J.JBUSRES.2021.08.011.

[48] K. M. Kniffin et al., "COVID-19 and the workplace: Implications, issues, and insights for future research and action," Am. Psychol., vol. 76, no. 1, pp. 63-77, 2021, doi: 10.1037/AMP0000716.

[49] J. Wosik et al., "Telehealth transformation: COVID19 and the rise of virtual care," J. Am. Med.

Informatics Assoc., vol. 27, no. 6, pp. 957-962, Jun. 2020, doi: 10.1093/JAMIA/OCAA067.

[50] D. Blei, L. Carin, and D. Dunson, "Probabilistic topic models," IEEE Signal Process. Mag., vol. 27, no. 6, pp. 55-65, 2010, doi: 10.1109/MSP.2010.938079.

[51] J. W. Mohr and P. Bogdanov, "Introduction-Topic models: What they are and why they matter," Poetics, vol. 41, no. 6, pp. 545-569, 2013, doi: 10.1016/j.poetic.2013.10.001.

[52] M. Mustak, J. Salminen, L. Plé, and J. Wirtz, "Artificial intelligence in marketing: Topic modeling, scientometric analysis, and research agenda," J. Bus. Res., vol. 124, pp. 389-404, Jan. 2021, doi: 10.1016/J.JBUSRES.2020.10.044.

[53] T. Schmiedel, O. Müller, and J. vom Brocke, "Topic Modeling as a Strategy of Inquiry in Organizational Research: A Tutorial With an Application Example on Organizational Culture," Organ. Res. Methods, vol. 22, no. 4, pp. 941-968, 2019, doi: $10.1177 / 1094428118773858$. 